\title{
CULTURAL DIFFERENCES IN SELF-PERCEPTIONS OF ABILITY, CONFIDENCE, AND PERCEPTIONS OF DIFFICULTY: PEDAGOGICAL IMPLICATIONS FOR THE LANGUAGE CLASSROOM
}

Anthony Sellick, James Bury

Shumei University, Japan

Phone: +81(0)47-488-2111, E-Mail: sellick@mailg.shumei-u.ac.jp

\begin{abstract}
With the Japanese government aiming to increase the proportion of foreign students attending Japanese universities to 10 percent by 2020, it is important to understand the different perceptions students have. This paper reports on a comparison between students from Confucian heritage culture (CHC) countries and students from nonConfucian Heritage Culture countries. The study found significant differences in the nonCHC students' self-assessments of English language ability and in their confidence in using English, while no differences were found in perceptions of course difficulty or in final grades. The report briefly discusses some of the pedagogical implications of teaching classes with mixed cultural traditions.
\end{abstract}

Key words: perceived difficulty, student beliefs, Confucian-heritage cultures

\section{INTRODUCTION}

In 2008, the Japanese government announced a policy initiative to increase the number of foreign students studying in Japan at the tertiary level to $10 \%$ of the total, or 300,000 students (MEXT, 2008). The make-up of foreign students studying in Japan includes students from countries which share a Confucian heritage with Japan and those which do not. As most university courses in Japan have compulsory English language classes as part of their syllabus, Japanese students are likely to increasingly find themselves studying together with foreign students. However, it is unclear whether students from Confucian heritage cultures (hereafter $\mathrm{CHC}$ ) report self-perceptions of ability differently to students from non-CHC countries. Since students' self-perceptions of ability (Li et al, 2007) and self-efficacy (Katz et al, 2014) are related to student perception of task difficulty, it is important for instructors to be aware of how these perceptions differ among students with different cultural heritages. In this paper, we describe an attempt to assess $\mathrm{CHC}$ and non-CHC students' perceptions of ability, confidence, and course difficulty in EFL courses in a private Japanese university. 


\section{LITERATURE REVIEW}

The constructivist paradigm of education indicates that increasing student involvement in their own learning can lead to improved learning outcomes (Guthrie et al, 2004). This can be of particular importance when learning a foreign language as the freedom to explore and make errors is an important part of the process of acquiring competence in, and understanding of the nuances of, the target language (Locklin, 2013).

However, students' own beliefs about their own abilities and the best way to learn can be a barrier to effective learning. Students that are over-confident can become frustrated at their perceived lack of progress, while students that lack confidence can easily become demotivated and give up, for example (Savaşç, 2014). Kruger and Dunning (1999) showed that students who are native speakers of English were considerably overconfident when self-assessing their English grammar abilities, predicting on average that their performance in a test would be almost 20 percentage points higher than what was actually achieved. Furthermore, it was found that the poorest performing students exhibited the greatest degree of relative over-confidence. Kruger and Dunning's (1999) findings demonstrated that poorly performing, over-confident students lacked the metacognitive capabilities to be able to accurately assess their own shortcomings.

While many subsequent studies have obtained similar results, there is evidence that individuals from CHC countries tend to under-estimate their abilities (Heine et al, 2001). Students from Confucian heritage cultures, in particular China, Japan, Singapore, South Korea, Taiwan, and Vietnam, are often characterised as promoting collectivist attitudes over individualism, deferring to teachers as authorities, being passive learners, having weak critical thinking skills, and as having difficulty understanding plagiarism (Tran, 2013). However, some aspects of this set of characteristics have been challenged as artefacts of the educational focus adopted by the countries in question (Tran, 2013), and as resulting from a political expediency that encourages a passive citizenry (O'Dwyer, 2003). Furthermore, some research has found that rather than under-estimating their abilities, students from $\mathrm{CHC}$ countries instead demonstrated greater accuracy in their self-assessments (Park et al, 2016) and were no more likely to make comparative judgements than students from non-CHC countries (Endo, 2007).

Nonetheless, for teachers in the Japanese context who are teaching, or will teach, mixed nationality classes, having some indication of how students from $\mathrm{CHC}$ and non$\mathrm{CHC}$ countries may vary in their self-assessments of their English abilities could be of some use. Consequently, in this paper we report on an attempt to identify some areas of difference and similarity in self-assessment among students of different nationalities and to isolate these differences from differences in actual ability.

\section{RESEARCH QUESTIONS}

In this study, we sought to find answers for the following hypotheses:

Hypothesis 1. There is no difference in relative ratings of the importance of five English skills between students from $\mathrm{CHC}$ countries and students from non-CHC countries.

Hypothesis 2. There is no difference in self-assessments of English language ability between students from $\mathrm{CHC}$ countries and students from non-CHC countries.

Hypothesis 3. There is no difference in self-assessments of confidence in using English language between students from $\mathrm{CHC}$ countries and students from non-CHC countries. 
Hypothesis 4. There is no difference in self-assessments of the difficulty of English language course material between students from $\mathrm{CHC}$ countries and students from non-CHC countries.

Hypothesis 5. There is no difference in self-assessments of English language ability among students from different $\mathrm{CHC}$ countries.

Hypothesis 6. There is no difference in self-assessments of confidence in using English language among students from different $\mathrm{CHC}$ countries.

Hypothesis 7. There is no difference in self-assessments of the difficulty of English language course material among students from different $\mathrm{CHC}$ countries.

Hypothesis 8. There is no difference in final course grades between students from $\mathrm{CHC}$ countries and students from non-CHC countries.

Hypothesis 9. There is no difference in final course grades among students from different CHC countries.

\section{PARTICIPANTS}

261 students (171 male, 90 female; median age 20) from ten South, South-East, and East Asian countries (see Table 1, below) attending a private four-year university in Japan participated in the study.

Table 1 Distribution of Participant Nationality

\begin{tabular}{lc}
\hline Country of Origin & No. of Participants \\
\hline Japan & 198 \\
Nepal & 34 \\
China & 11 \\
Vietnam & 10 \\
Sri Lanka & 2 \\
Indonesia & 1 \\
Taiwan & 1 \\
Philippines & 1 \\
India & 1 \\
Bangladesh & 1 \\
Not Given & 1 \\
\hline Total & 261 \\
\hline
\end{tabular}

Students at the university are required to obtain passing grades in at least elementary level EFL courses during their time at the university. The majority of students opt to take these courses in either their freshman or sophomore years, although a small number prefer to take them in their junior or senior years (see Table 2, below).

Table 2 Distribution of Participant Grade

\begin{tabular}{lc}
\hline Academic Year & No. of Participants \\
\hline First Year $\cdot$ Freshman & 113 \\
Second Year $\cdot$ Sophomore & 125 \\
Third Year $\cdot$ Junior & 18 \\
Fourth Year $\cdot$ Senior & 5 \\
\hline Total & 261 \\
\hline
\end{tabular}




\section{METHODOLOGY}

Students were asked to complete a 19-item questionnaire during the final lesson of their course. The questionnaire consisted of three items which collected demographic data, one ranking item, and 15 Likert items.

The questionnaires were anonymous and participation was purely voluntary. The data was collected during the final lesson of the course for three reasons:

- By collecting the data after all graded work had been completed, it was hoped that the students would participate voluntarily rather than doing so out of a feeling of obligation or that it was a necessary part of the course.

- By collecting the data after all graded work had been completed, it was hoped that the students would return their honest opinions.

- By collecting the data at the end of the course, students would be able to adequately reflect on their experiences through the course.

- By collecting the data at the end of the course, it would be possible to compare students' self-reported ability and confidence levels with their final course assessments.

\section{RESULTS}

Of the 276 questionnaires distributed, 256 were returned, representing a $92.8 \%$ response rate.

The relative importance of different English skills to the students' future careers were collected and analysed via Student t-Tests. The results obtained are shown in Table 3, below.

Table 3 Relative rating of English skill importance

\begin{tabular}{lccccccc}
\hline & \multicolumn{3}{c}{ CHC Students } & \multicolumn{3}{c}{ Non-CHC Students } & \\
\cline { 2 - 6 } English & Mean & Standard & Number of & Mean & Standard & Number of & \\
Skill & $\begin{array}{c}\text { Rating } \\
\text { Deviation }\end{array}$ & $\begin{array}{c}\text { Students } \\
\text { Dating }\end{array}$ & $\begin{array}{c}\text { Deviation } \\
\text { Students }\end{array}$ & $p$ \\
\hline Speaking & 1.9 & 1.3 & 215 & 1.8 & 1.3 & 40 & 0.655 \\
Listening & 2.2 & 1.2 & 215 & 2.2 & 1.2 & 40 & 1.000 \\
Vocabulary & 2.9 & 1.4 & 214 & 2.5 & 1.6 & 40 & 0.106 \\
Reading & 3.1 & 1.3 & 216 & 2.6 & 1.4 & 40 & $0.028^{*}$ \\
Writing & 3.6 & 1.4 & 214 & 3.0 & 1.7 & 40 & $0.017^{*}$ \\
\hline \multicolumn{7}{c}{ (* indicates statistical significance at 0.05 or better) }
\end{tabular}

When analysed via Student t-Tests, it was found that students from CHC countries rated English reading and writing skills as significantly less important to their future careers than students from non-CHC countries. Therefore, Hypothesis 1 must be partially rejected.

In items 5 through 19 of the questionnaire, students were asked to indicate their selfassessments of ability, confidence in using, and perceived difficulty of course materials for each of the five English skills on a 10-point Likert scale. The ratings provided by the $\mathrm{CHC}$ and non-CHC students were then analysed via Student t-Tests, and the results obtained are summarized in Table 4 , below. 
Table 4 Comparing self-assessed ability, self-assessed confidence, and perceived course material difficulty for five English skills and between $\mathrm{CHC}$ and non-CHC students via t-Tests

\begin{tabular}{llcccccc}
\hline & & \multicolumn{2}{c}{ CHC students } & \multicolumn{2}{c}{ Non-CHC students } & & \\
\cline { 2 - 6 } & English skill & $\overline{\mathrm{x}}$ & $\underline{\sigma}$ & $\overline{\mathrm{x}}$ & $\underline{\sigma}$ & $p$ & $g$ \\
\hline Self-assessed & Reading & 5.3 & 1.8 & 6.6 & 1.5 & $0.0001^{*}$ & 0.74 \\
& Speaking & 5.1 & 2.0 & 5.8 & 1.4 & $0.0351^{*}$ & 0.36 \\
& Listening & 5.4 & 2.0 & 6.1 & 1.7 & $0.0387^{*}$ & 0.36 \\
& Writing & 4.7 & 1.9 & 6.3 & 1.3 & $0.0001^{*}$ & 0.88 \\
& Vocabulary & 4.4 & 1.8 & 5.4 & 1.5 & $0.0011^{*}$ & 0.57 \\
\hline Self-assessed & Reading & 5.1 & 2.1 & 6.5 & 1.8 & $0.0001^{*}$ & 0.68 \\
confidence & Speaking & 5.0 & 2.3 & 5.5 & 1.6 & 0.1515 & - \\
& Listening & 5.2 & 2.1 & 6.0 & 1.8 & $0.0246^{*}$ & 0.39 \\
& Writing & 4.6 & 2.1 & 6.2 & 1.7 & $0.0001^{*}$ & 0.78 \\
& Vocabulary & 4.4 & 2.1 & 5.4 & 1.5 & $0.0044^{*}$ & 0.50 \\
\hline Perceived & Reading & 5.4 & 2.0 & 5.6 & 2.1 & 0.5648 & - \\
course material & Speaking & 5.4 & 2.1 & 5.4 & 1.8 & 1.0000 & - \\
difficulty & Listening & 5.4 & 2.1 & 5.2 & 2.0 & 0.5777 & - \\
& Writing & 5.5 & 2.0 & 5.2 & 1.7 & 0.3739 & - \\
& Vocabulary & 5.5 & 2.0 & 5.4 & 1.7 & 0.7667 & - \\
\hline
\end{tabular}

(* indicates statistical significance at 0.05 or better)

The results of the analysis showed that the self-assessed ratings non-CHC students assigned themselves for all areas of English ability were significantly higher than the self-assessed ratings $\mathrm{CHC}$ students assigned themselves. Furthermore, with the exception of confidence in speaking English, the self-assessed ratings non-CHC students assigned themselves confidence in using English were significantly higher than the self-assessed ratings $\mathrm{CHC}$ students assigned themselves. Finally, there were no significant differences between the ratings non-CHC and $\mathrm{CHC}$ students assigned to the perceived difficulty of the course materials. Consequently, hypotheses 2 through 4 must be rejected.

In order to ascertain whether there were any variations among students from different $\mathrm{CHC}$ countries, and the direction of any such differences, their self-assessments of ability, confidence in using, and perceived difficulty of course materials for each of the five English skills were analysed via ANOVA, and the data and ANOVA results are summarised in Table 5, below.

The ANOVA results indicate that there is no significant variation among students from $\mathrm{CHC}$ countries with regards to their self-assessed English ability and confidence in using English. Consequently, hypotheses 5 and 6 must be accepted. However, with regards to perceived course material difficulty, at least for speaking, listening, and writing materials, students from different CHC countries did vary significantly in the ratings given, and consequently, hypothesis 7 must be tentatively rejected.

In order to determine if there was any variation in final course grades between $\mathrm{CHC}$ and non-CHC students, their data was analysed via a Student t-Test, and the results obtained are described in Table 6, below. 
Table 5 Relationships between self-perceived ability, self-perceived confidence, and perceived course material difficulty for five English skills among students from different CHC countries, analysed via ANOVA

\begin{tabular}{|c|c|c|c|c|c|c|c|c|c|c|}
\hline & \multirow[b]{2}{*}{ English skill } & \multicolumn{2}{|c|}{$\begin{array}{l}\text { Japanese } \\
\text { students }\end{array}$} & \multicolumn{2}{|c|}{$\begin{array}{l}\text { Chinese } \\
\text { students }\end{array}$} & \multicolumn{2}{|c|}{$\begin{array}{l}\text { Vietnamese } \\
\text { students }\end{array}$} & \multirow[b]{2}{*}{$F$} & \multirow[b]{2}{*}{$p$} & \multirow[b]{2}{*}{$\eta^{2}$} \\
\hline & & $\overline{\bar{x}}$ & $\sigma$ & $\overline{\mathrm{x}}$ & $\sigma$ & $\overline{\mathrm{x}}$ & $\sigma$ & & & \\
\hline \multirow{5}{*}{$\begin{array}{l}\text { Self- } \\
\text { assessed } \\
\text { ability }\end{array}$} & Reading & 5.4 & 1.8 & 5.3 & 2.1 & 5.1 & 2.4 & 0.137 & 0.872 & - \\
\hline & Speaking & 5.1 & 1.9 & 5.0 & 2.2 & 4.8 & 2.7 & 0.122 & 0.885 & - \\
\hline & Listening & 5.4 & 2.0 & 5.2 & 2.4 & 4.6 & 2.2 & 0.772 & 0.463 & - \\
\hline & Writing & 4.7 & 1.9 & 4.2 & 1.7 & 4.9 & 2.4 & 0.422 & 0.656 & - \\
\hline & Vocabulary & 4.4 & 1.8 & 4.0 & 1.3 & 4.2 & 2.4 & 0.301 & 0.740 & - \\
\hline \multirow{5}{*}{$\begin{array}{l}\text { Self- } \\
\text { assessed } \\
\text { confidence }\end{array}$} & Reading & 5.1 & 2.1 & 5.3 & 1.7 & 4.8 & 2.5 & 0.151 & 0.860 & - \\
\hline & Speaking & 4.9 & 2.3 & 5.9 & 1.8 & 4.9 & 2.7 & 0.989 & 0.374 & - \\
\hline & Listening & 5.2 & 2.1 & 5.8 & 2.3 & 4.4 & 2.0 & 1.167 & 0.313 & - \\
\hline & Writing & 4.6 & 2.1 & 5.1 & 1.7 & 4.2 & 2.4 & 0.494 & 0.611 & - \\
\hline & Vocabulary & 4.4 & 2.1 & 4.5 & 1.1 & 4.4 & 2.5 & 0.012 & 0.988 & - \\
\hline \multirow{5}{*}{$\begin{array}{l}\text { Perceived } \\
\text { course } \\
\text { material } \\
\text { difficulty }\end{array}$} & Reading & 5.5 & 2.0 & 4.3 & 1.1 & 4.8 & 2.4 & 2.390 & 0.094 & - \\
\hline & Speaking & 5.6 & 2.0 & 4.1 & 1.4 & 4.4 & 2.4 & 4.487 & $0.012 *$ & 0.04 \\
\hline & Listening & 5.5 & 2.0 & 4.0 & 1.1 & 5.1 & 2.8 & 3.028 & $0.050^{*}$ & 0.03 \\
\hline & Writing & 5.6 & 2.0 & 4.1 & 1.1 & 4.7 & 2.3 & 3.804 & $0.024 *$ & 0.03 \\
\hline & Vocabulary & 5.6 & 2.0 & 4.3 & 1.3 & 5.0 & 2.5 & 2.545 & 0.081 & - \\
\hline
\end{tabular}
(* indicates statistical significance at 0.05 or better)

Table 6 Comparing final course grades between $\mathrm{CHC}$ and non-CHC students via t-Tests

\begin{tabular}{lcc}
\hline & CHC students & Non-CHC students \\
\hline Mean Grade $(\overline{\mathrm{x}})$ & 78.06 & 76.89 \\
Standard Deviation $(\sigma)$ & 14.827 & 10.403 \\
Number of students $(n)$ & 220 & 41 \\
\hline \multicolumn{2}{c}{$p$} & 0.6134 \\
\hline \multicolumn{2}{c}{$(*$ indicates statistical significance at 0.05 or better) }
\end{tabular}

These results indicate that there was no statistical significance between the final course grades awarded to students from $\mathrm{CHC}$ countries and students from non-CHC countries. Consequently, hypothesis 8 is accepted.

The final analysis undertaken was to determine if there was any variation in final course grades among students from different CHC countries. The data for these students was analysed via ANOVA, and the results obtained are described in Table 7, below.

Table 7 Comparing final course grades among students from different $\mathrm{CHC}$ countries via ANOVA

\begin{tabular}{cccc}
\hline & Japanese students & Chinese students & Vietnamese students \\
\hline Mean Grade $(\overline{\mathrm{x}})$ & 78.40 & 75.48 & 72.70 \\
Standard Deviation $(\sigma)$ & 14.491 & 10.662 & 23.688 \\
Number of students $(n)$ & 198 & 11 & 10 \\
\hline$F$ & 0.853 & & \\
$p$ & 0.427 &
\end{tabular}


These results indicate that there was no statistical significance in final course grades awarded to students from different $\mathrm{CHC}$ countries. Consequently, hypothesis 9 is accepted.

\section{DISCUSSION}

The results obtained in this study show that, when asked to provide self-assessments of their English ability, students from non-CHC countries rate themselves as significantly more able than students from CHC countries do. The same pattern was found with regard to confidence in using English, with students from non-CHC countries rating their confidence as higher than that of students from CHC countries, with the exception of confidence when speaking English. One possible explanation for this exception is that the courses in question were taught by native teachers of English, rather than Japanese teachers of English. There is some evidence that students treat their foreign language teacher as a language role model, with native-speaking teachers being viewed as an "unattainable" model compared to nonnative speaking teachers (Sellick et al, 2014). Furthermore, the perceived role of the teacher has been connected to student anxiety when using a foreign language (Abu-Rabia, 2004). As a result, being taught by native teachers of English may have had the result of causing all students to downgrade their confidence in this area.

Despite the differences in self-assessed ability and confidence with English, there was no statistically significant difference in how difficult the students found the course materials, nor in their final course grades. This finding does provide some support for the idea that students from $\mathrm{CHC}$ countries are more likely to under-estimate their ability than students from non-CHC countries.

Comparing students from different $\mathrm{CHC}$ countries found that there were few differences among the countries, with the exception of ratings given on the difficulty of speaking, listening, and writing course materials. These findings may reflect different teaching approaches in the respective countries' educational systems, but the very low effect sizes associated with these findings mean that we cannot be confident that these findings are not statistical artefacts. Further research into the differences, if any, among the different CHC countries is indicated.

There are several limitations to this study, first and foremost being the relatively small sample size of non-CHC students. However, although a relatively small group, the non-CHC students do represent approximately a fifth of the total number of students taking part in the study, which is a reasonable representation of the ethnic make-up of the student body as a whole.

A more pressing limitation of the study is that the majority of non-CHC students are from South Asia, primarily from Nepal, with the result that the characteristics of students from other countries may have been overly diluted. As a result, the question must be asked whether this study actually compares students from Confucian heritage cultures with students from Hindu heritage cultures and not non-CHC students in general.

This study tries to link the students' self-assessments of English ability, confidence in using English, and perception of course difficulty with the students' grades in order to ascertain the direction of any self-reporting bias. However, it was not possible to link the students' self-reports with the specific English skills in question. This is unfortunate as it means it is not possible to ascertain, at this point, whether there is variation in selfreporting and performance among the English skills between students from $\mathrm{CHC}$ and non-CHC countries. 
Finally, this study examines students' self-reported assessments of English ability, confidence in using English, and perceptions of course difficulty. It does not address whether students from $\mathrm{CHC}$ and non-CHC countries differ in their expectations of university study and university lecturers. We hope to address this question in further research.

\section{CONCLUSION}

The ongoing MEXT project to increase the number of foreign students attending Japanese universities provides a number of challenges and opportunities for teachers of English as a foreign language. Teachers who have become used to the ideal of the CHC student, one who is 'quiet, passive and obedient [...] who performs well on tests,' (Nozaki, 2003, p.28), may find the apparent increased enthusiasm to participate and produce answers (however inaccurate) among non-CHC students as challenging, refreshing, or both. Teachers from a non-CHC background may view such students as closer to the ideal of being creative, inquiring, and keen to share their opinions with the teacher (Nemoto, 1999, p.51). However, this can run the risk of allowing non-CHC students to dominate the classroom, with the result that $\mathrm{CHC}$ students can inadvertently become side-lined and miss out on chances to participate. Furthermore, there is a danger that teachers misinterpret student enthusiasm with ability and allow this to bias their assessments.

Students from Confucian heritage cultures (CHC) and students from cultures with different traditions make significantly different self-appraisals with regards to their abilities and confidence with English. As the number of students from non-CHC countries attending Japanese universities increases, educators will need to familiarise themselves with these differences, and will also find themselves facing new challenges and opportunities in improving the provision of English language education in Japanese tertiary educational institutions.

However, careful planning of classroom activities can circumvent these potential issues and ensure maximal participation of all students. Providing opportunities for $\mathrm{CHC}$ and nonCHC students to work and practice together removes much of the pressure to produce the 'correct' answer that CHC students may feel when questioned by a teacher. Furthermore, CHC students may benefit from the more communication-lead, error-tolerant approach taken by non-CHC students. Conversely, non-CHC students may benefit from a slower paced, accuracy-focused approach taken by CHC students. Research conducted in both $\mathrm{CHC}$ and non-CHC countries has found that nearly equal weights are assigned to the opinions of others irrespective of any real or perceived differences in ability (Mahmoodi et al, 2015). While this equality bias may be a disadvantage in many situations, in the EFL classroom, it can be a positive as it encourages individuals of different cultural approaches to treat each other with equity. 


\section{REFERENCES}

Abu-Rabia, S. 2004. "Teachers' role, learners' gender differences, and FL anxiety among seventh-grade students studying English as a FL." Educational Psychology 24, no.5: 711-721.

Endo, Y. 2007. "Optimistic and pessimistic biases and comparative judgmental processes in Japan: Do people really compare themselves to their peers?" Asian Journal of Social Psychology, 10, no.4: 224-232.

Guthrie, J. T., Wigfield, A., Barbosa, P., Perencevich, K. C., Taboada, A., Davis, M. H., Scafiddi, N. T., \& Tonks, S. 2004. "Increasing reading comprehension and engagement through concept-oriented reading instruction." Journal of Educational Psychology. 96, no.3: 403-423.

Heine S. J., Kitayama S., Lehman D. R., Takata T., Ide E., Leung C., \& Matsumoto H. 2001. "Divergent consequences of success and failure in Japan and North America: An investigation of self-improving motivations and malleable selves." Journal of Personality and Social Psychology, 81: 599-615.

Kruger, J. \& Dunning, D. 1999. "Unskilled and Unaware of It: How Difficulties in Recognizing One's Own Incompetence Lead to Inflated Self-Assessments.” Journal of Personality and Social Psychology, 77, no.6: 1121-1134.

Li, W., Lee, A., \& Solmon, M. 2007. "The role of perceptions of task difficulty in relation to self-perceptions of ability, intrinsic value, attainment value, and performance." European Physical Education Review, 3, no.3: 301-318.

Locklin, B. S. 2013. "Learning from our mistakes: Difficulty and insight in the literature classroom." Journal of the Midwest Modern Language Association, 46, no.1: 55-69.

Mayer, R. E. 2004. "Should there be a three-strikes rule against pure discovery learning?" American Psychologist, 59, no.1: 14-19.

Mahmoodi A., Bang, D., Olsene, K., Zhao, Y. A., Shih, Z., Broberg, K., Safavi, S., Hang, S., Ahmadabadi, M. N., Frith, C. D., Roepstorff, A., Rees, G., \& Bahrami, B. 2015. "Equality bias impairs collective decision-making across cultures." PNAS, 112, no.12: 3835-3840.

MEXT. 2008. Outline of the Student Exchange System: Study in Japan and Abroad. Tokyo: Ministry of Education, Culture, Sports, Science and Technology, Japan (MEXT).

Nemoto, Y. 1999. The Japanese education system. Parkland, Florida: Universal Publishers.

Nozaki, K.N. 1993. "The Japanese student and the foreign teacher." In Wadden (ed.), A Handbook for teaching English in Japanese colleges and universities, Oxford: Oxford University Press.

O’Dwyer, S. 2003. "Democracy and Confucian Values." Philosophy East and West, 53, no. $1: 39-63$.

Park, S. W., Tignor, S. M., Min, J. J., \& Heo, Y. H. 2016. "Accuracy and bias in selfperception of performance: Narcissism matters in Korea as well." Korean Social Science Journal, 43, no.2: 29-43.

Savaşç, M. 2014. "Why are some students reluctant to use L2 in EFL speaking classes? An action research at tertiary level." Procedia - Social and Behavioral Sciences, 116: 2682-2686.

Sellick, A., Bury, J., Yamamoto, K., \& Watanabe, A. 2014. "Encouraging Incidental English Communication in Japanese English Classes, Part 1: Student Attitudes." Shumei University Journal, 11: 167-190.

Tran, T. T. 2013. "Is the learning approach of students from the Confucian heritage culture problematic?" Educational Research for Policy and Practice, 12, no.1: 57-65. 


\section{APPENDIX: DEGREES OF DIFFICULTY QUESTIONNAIRE}

Please help us to improve this course by giving us your feedback.

1. Gender:

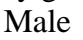

2. Current year of study:

1st

2nd $\quad 3$ rd

Female

3. Country of origin:

Japan Other (Which country?

Other

4. Rank the English skills by how important you think they to your future goals $(1=$ most important, 5 = least important).

\begin{tabular}{llll}
- & Reading & - & Speaking \\
- & Listening & - & Writing \\
\hline & Knowledge of vocabulary & &
\end{tabular}

On a scale of $1-10(1=$ very low, $10=$ very high $)$, how would you rate your ability in the following categories?

5. English Reading.

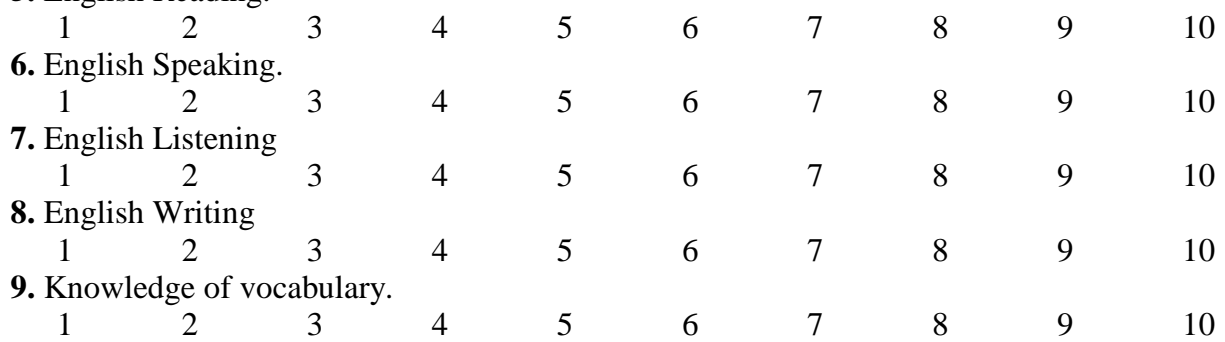

On a scale of $1-10(1=$ very low, $10=$ very high $)$, how confident are you in the following categories?

10. English Reading.

$\begin{array}{llllllllll}1 & 2 & 3 & 4 & 5 & 6 & 7 & 8 & 9 & 10\end{array}$

11. English Speaking.

$\begin{array}{llllllllll}1 & 2 & 3 & 4 & 5 & 6 & 7 & 8 & 9 & 10\end{array}$

12. English Listening

$\begin{array}{llllllllll}1 & 2 & 3 & 4 & 5 & 6 & 7 & 8 & 9 & 10\end{array}$

13. English Writing

$\begin{array}{llllllllll}1 & 2 & 3 & 4 & 5 & 6 & 7 & 8 & 9 & 10\end{array}$

14. Knowledge of vocabulary.

$\begin{array}{llllllllll}1 & 2 & 3 & 4 & 5 & 6 & 7 & 8 & 9 & 10\end{array}$

On a scale of $1-10(1=$ Not at all, $10=$ A great deal $)$, how difficult did you find the materials in this course relating to the following categories?

15. English Reading.

$\begin{array}{llllllllll}1 & 2 & 3 & 4 & 5 & 6 & 7 & 8 & 9 & 10\end{array}$

16. English Speaking.
1

$\begin{array}{ccccccccc}\text { 17. English Listening } & & & & 6 & 7 & 8 & 9 & 10\end{array}$

$\begin{array}{ccccccccc}\text { 18. English Writing } & & & & & & & \\ 1 & 2 & 3 & 4 & 5 & 6 & 7 & 8 & 9\end{array}$

19. Knowledge of vocabulary. 